Article

\title{
Retention of Atmospheric Particles by Local Plant Leaves in the Mount Wutai Scenic Area, China
}

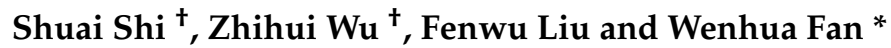 \\ Environmental Engineering Laboratory, College of Resource and Environment, Shanxi Agricultural University, \\ Jinzhong 030801, China; 18534134455@163.com (S.S.); oldfive6699@163.com (Z.W.); liufenwu@sxau.edu.cn (F.L.) \\ * Correspondence: fanwh@sxau.edu.cn; Tel.: +86-354-628-6980 \\ + These authors contributed equally to this work.
}

Academic Editor: Robert W. Talbot

Received: 29 June 2016; Accepted: 3 August 2016; Published: 8 August 2016

\begin{abstract}
To evaluate the characteristics of atmospheric particle retention by plant leaves during the tourism season in Buddhism-based scenic areas, plants distributed in the core area of the Mount Wutai scenic area were selected for study: Populus davidiana (Po. davidiana), Rosa hugonis Hemsl. (R. hugonis), Betula platyphylla Suk. (B. platyphylla), Rosa xanthina Lindl. (R. xanthina), Periploca sepium Bunge (Pe. sepium), Spiraea salicifolia L. (S. salicifolia), Vitex negundo var. Heterophylla (V. negundo var. heterophylla) and Pinus tabuliformis Carrière (Pi. tabuliformis). Before rain, the atmospheric suspended particle-retaining weight of the plant leaves varied in the range of $6.95 \pm 1.55$ (Pi. tabuliformis) to $38.60 \pm 18.32 \mathrm{mg} / \mathrm{cm}^{2}$ (Po. davidiana); the light shaded areas caused by particles on leaves were in the range of $7.25 \pm 0.04$ (Pi. tabuliformis) to $126.50 \pm 6.66 \mathrm{~cm}^{2} /$ leaf (Po. davidiana); and the atmospheric particle-retaining horizontal density of leaves varied in the range of $110 \pm 2$ (Pi. tabuliformis) to $255 \pm 11$ per $\mathrm{cm}^{2}$ (Po. davidiana). After rain, the atmospheric suspended particle-retaining quality of plant leaves varied in the range of $0.65 \pm 0.23$ (Pi. tabuliformis) to $3.50 \pm 1.83 \mathrm{mg} / \mathrm{cm}^{2}$ (Po. davidiana); the light shaded areas by particles on leaves were in the range of $4.26 \pm 0.02$ (Pi. tabuliformis) to $45.96 \pm 2.42 \mathrm{~cm}^{2} /$ leaf $(P o$. davidiana); and the atmospheric particle-retaining horizontal density of leaves was in the range of $97 \pm 2$ (Pi. tabuliformis) to $147 \pm 7$ per $\mathrm{cm}^{2}$ (Po. davidiana). The broad-leaved plants, particularly Po. davidiana, R. hugonis and B. platyphylla, were appropriate species for purification of atmospheric particles. Plants with lower dust-retention abilities than the above three species (e.g., R. xanthina, Pe. sepium, S. salicifolia and V. negundo var. heterophylla) could be alternative plants for purification. However, the needle-leaved plant Pi. tabuliformis was not recommended as a tree species for purification of atmospheric particles in the core area of the Mount Wutai scenic area.
\end{abstract}

Keywords: particulate matter; leaves; Dust Retention; light shading area; retention density

\section{Introduction}

With the highlighting of atmospheric environmental problems in cities and the increase in resident work pressure, relaxation and travel in natural scenic areas has been one way for people to pursue a healthy life. The number of domestic tourists in China reached $3.6 \times 10^{9}$ in 2014, and it is predicted that this number will rise by $39 \%$ in 2020 . In addition, the first choice for travel by most tourists is forest parks with better air quality and perfect green vegetation. However, nearly 10,000 Buddhist temples are distributed in China's forest parks [1-3]. In these regions, long-term extensive burning of incense as well as the combustion of fossil fuel and biomass products with increased rates of pilgrimage have year-by-year aggravated the atmospheric particulate pollution in Buddhism scenic areas. Through research on the atmospheric environment of two temples in Hong Kong, Wang et al. [4] found that during the peak of incense burning, the average concentration of benzene in the environment was more than eight times the air quality standard value for rooms, office buildings and public places. 
Similarly, research on surrounding air quality of some temples in northern China showed that the formaldehyde concentration reached $0.97 \mathrm{mg} / \mathrm{m}^{3}$ during the peak of incense burning, which was nine times the indoor air quality standard value in China [5]. The research of Navasumrit et al. indicated that long-term exposure of temple staff to incense smoke increased DNA damage probability and decreased DNA repair capacity [6]. In consideration of the above pollution situation of atmospheric particles in Buddhism scenic areas of forest parks and the damage to the human body, work on prevention of atmospheric particulate pollution during tourist activity is an environmental issue in pressing need of attention.

The vegetation coverage in forest parks is relatively high, and the vegetation results in lower temperatures and higher relative humidity for such scenic areas; however, these meteorological conditions are also conductive to the settling of atmospheric particles on leaves and the ground [7]. Plant leaves have retention and adsorption capacities for atmospheric particulate pollutants because of their unique surface characteristics and leaf crown distribution, and can retain particulate pollutants as well as adsorb vapor-phase pollutants to various extents. For example, Schaubroeck et al. used modeling to explore the role of forests in Europe in the reduction of atmospheric fine particles, and calculated the variation in the elimination rate of the particles during the forest growth process [8]. Terzaghi et al. found that plants had retention effects related to atmospheric particles, wherein the particle size, wind speed and plant species all affected the deposition effect of particles on leaves [9]. However, there were significant differences in atmospheric particle retention capacities of leaves according to factors including seasonal aspect, leaf surface structures of species and tree size. Research by Nguyen et al. indicated that in urban forest systems, shrubs and broad-leaved forest had the highest air $\mathrm{PM}_{2.5}$ elimination efficiency when the leaves were fully developed. However, in the season of leaf defoliation, needle-leaved trees and mixed tree species had the highest elimination efficiency for air-borne dust [10]. Research by Wang et al. showed that particles were more easily retained if there were 1-2 $\mu \mathrm{m}$ ridged grooves on leaf surfaces or rough blade surfaces far from the rachis in broad-leaved plants [11]. Factors including leaf shape, leaf size, tree trunk and crown density explained the different capacities of $\mathrm{PM}_{2.5}$ retention in forests [12].

In addition, particulate pollutants adsorbed on leaf surfaces can have strong influences on various aspects of plant physiology, biochemistry and genotoxicity. For example, research indicated that atmospheric particles led to reductions in the pigment content of plant leaves, decreases in total sugar content and protein denaturation [13]. Research on Ficus religiosa, F. benghalensis, Mangifera indica, Dalbergia sissoo, Psidium guajava and Dendrocalamus strictus explored the seasonal variation trend of particle deposition on leaves, and found that an increase in atmospheric particles that settled on leaves of selected tree species led to a reduction in chlorophyll content and an increase in ascorbic acid [14]. Investigation of the effects of particles emitted from heavy-duty diesel engines showed that exposure to the soot suspension reduced the cellular mitosis capacity in root tips of broad bean [15]. Through research on leaf structures of mangrove forest around iron mining areas in Brazil as well as the chemical component and biological accumulation of their retentates, Arrivabene et al. found that iron particles in the atmospheric environment had slight effects on the stomata of mangrove leaves and the salinity balance in leaf cells. There was non-significant injury to leaf morphology or structure with different concentrations of iron particles and, simultaneously, most iron retained on leaf surfaces was absorbed by plants. Therefore, plantations of mangrove plants in iron mining areas were conductive to purification of iron particles [16].

However, there has been little research on the effects of leaves on the retention quality of atmospheric particles, light shading characteristics of leaf surfaces and the retention density of particles on leaves. In addition, there are also few reports on the effects of precipitation processes on these indexes.

Mount Wutai is located in Xinzhou city, Shanxi Province, China, and is a world-famous Buddhism natural scenic area with 3 million tourists per year visiting for pilgrimage and burning of incense. The core tourist area is surrounded by primeval forest of a national geological park, with high 
vegetation coverage. However, in previous studies and field investigations by this research group [17], this environment had the advantage of natural self-purification capacity, although atmospheric particulate pollution was still quite serious, and $50 \%$ of the sampled area had light pollution status [18]. Therefore, it is particularly relevant to explore the effects of vegetation species in forest scenic areas on particulate matter retention as well as the effects of particulate matter on the light shading area of leaves.

Mount Wutai was used in this research to study the atmospheric particle retention quality of plant leaves in a scenic area affected by tourist activities, analyze the variation in the shaded area on the leaf surfaces and the retention density before and after rain, as well as to evaluate the purification capacity coefficient of leaves. Tree species with high adsorption and lower residual particulate levels would be expected to improve the atmospheric particulate pollution in natural scenic areas, and prevention programs of atmospheric particulate pollution in scenic area were proposed to provide scientific data for managing the atmospheric environment in Buddhism scenic areas in Mount Wutai and Northern China generally.

\section{Experimental Methods}

\subsection{Sampling Method of Particles on Leaf Surfaces}

Based on previous results concerning vegetation in Mount Wutai conducted by this research group [17], the atmospheric particles on plant leaf surfaces in four different tourism functional areas of Mount Wutai, including incense-burning aggregated area at Wu Ye Temple where a lot of people use incense for worship, transportation hub at Manjusri Temple, residential district in the scenic area of Yang Bai Lin Village and primeval forest area at Nanshan Temple, were collected during 21-27 August 2014. In fact, the sampling process in this study lasted for one month (1-31 August 2014). However, there was no rain on the following days : 5 August 2014, 7-8 August 2014, 15-17 August 2014, 21-27 August 2014, 29 August 2014, 21-27 August 2014. This research paper chose the longest period of no rain days (21-27 August 2014). In addition, previous studies show that the accumulation of atmospheric particulate matter on the leaves from 4-7 days will reach a higher level [11]. Therefore, the conclusion of this study has certain degree of representation. The rainfall amount of Mount Wutai was $172.5 \mathrm{~mm}$ in August 2014. The period of rainfall was distributed over the following days: 8.1-8.4, 8.6, 8.9-8.14, 8.18-8.20, 8.28, 8.30-8.31. Sampling locations in this study are shown in Figure 1 . The characteristic plants with higher coverage and greater numbers in each sampling area were selected: Populus davidiana, Betula platyphylla Suk., Periploca sepium Bunge, Rosa hugonis Hemsl., Spiraea salicifolia L., R. xanthina Lindl., Vitex negundo var. heterophylla and Pinus tabuliformis Carrière. Plant samples were identified using the Plant Photo Bank of China established in the herbarium of the Institute of Botany, Chinese Academy of Sciences [19]. Plants collected soon after rain were used as blank controls and those collected one week after rain were used as working samples to ensure that some particles were retained on leaves. Dust retention of leaf surfaces differs with tree height; accordingly, the sampling heights for each tree species were basically similar. Combined with the actual growth states of each species in the sampling sites, the sampling heights were as follows: $2.0-6.0 \mathrm{~m}$ for Po. davidiana, B. platyphylla, Pe. sepium and Pi. Tabuliformis, and 1.5-2.0 m for R. hugonis, S. salicifolia, R. xanthina and V. negundo var. heterophylla. Ten tree samples were selected for each species, and well-developed leaves in different directions of the crown were collected. About 50 leaves of plants with large single leaf area (Po. davidiana and B. platyphylla) were collected, while about 80 leaves of plants with smaller single leaf area were collected. These leaves were immediately placed in dust-free airtight bags and sealed, with the sampling dates and sites marked. The leaves were brought back to the laboratory and stored at $4{ }^{\circ} \mathrm{C}$ in a refrigerator. 


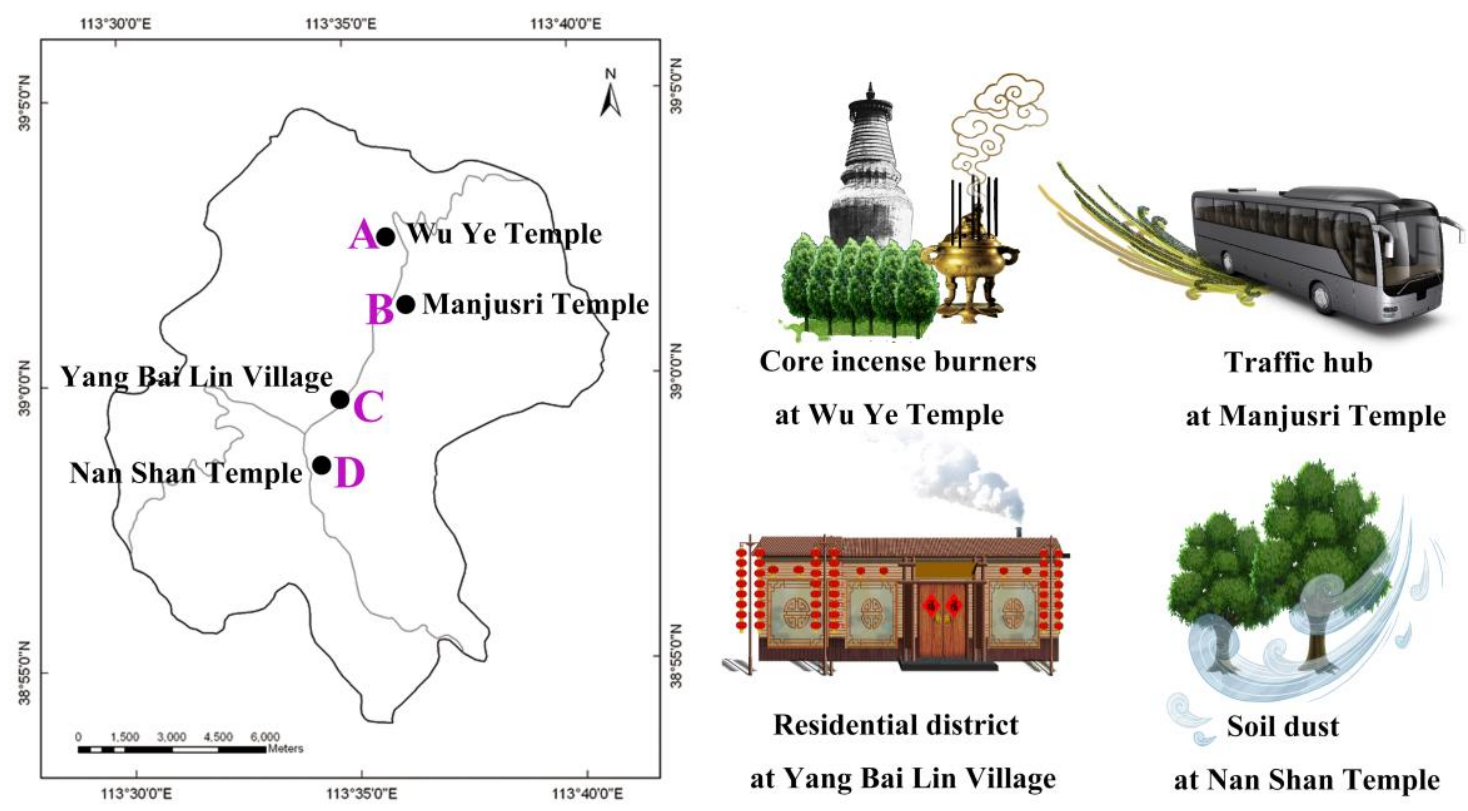

Figure 1. The distribution of the four sampling sites in Mount Wutai, Shanxi Province, China.

\subsection{Analysis of Particles on Leaves}

The samples of retained particles on leaves were analytically determined through an optical microscope (SMZ-168 type, production in MOTIC CHINA GROUP CO., LTD, Xiamen, China), using the method that follows.

(1) Twenty-five leaves of the same plant type were randomly selected, and the samples of upper/lower surfaces of each leaf of size $5 \mathrm{~mm} \times 5 \mathrm{~mm}$ were obtained. (Because most of the dominant plants in the core of the scenic area were Pinaceae plants, there were difficulties in identifying leaf upper/lower surfaces and this was of less practical significance. Therefore, the relatively fleshy side of the needle body of Pi. tabuliformis was nominated as the upper surface and the other side as the lower surface; and the upper/lower surfaces of the other plants were differentiated according to plant morphology.). Similar to the measurement standard used in leaves of broad-leaved plants (Twenty-five leaves of the same plant type with strong growth, similar leaf age and length were selected as one group), twenty-five clusters of pine needles were selected as one group for determination and examined under an optical microscope. The light shading density and area of atmospheric particles on leaves were observed and digital images taken, with three repetitions of each sample. The stored images were used for determination of particle horizontal density (Density 2D) and particle-retaining horizontal area (Area) through a microscopic image analysis system (Image-Pro Plus 6.0).

(2) Leaves of the same species were placed in a clean beaker and washed with distilled water (ten leaves of Po. davidiana and B. platyphylla were washed simultaneously, as were twenty leaves of the other species). The washing fluid was filtered by a glass fiber filter, and the glass fiber was then dried to constant weight at $40{ }^{\circ} \mathrm{C}$. The quality of retained particles on leaves was the quality difference between the weighed filter after drying and the clean filter, and was equally assigned to each leaf. Three replications of washing, filtration and determination of retention were conducted for each species. Image-Pro Plus 6.0 was applied to determine the leaf area to allow expression of retention of particles per unit area of leaves.

\subsection{Evaluation of Leaf Purification Capacity}

The plants best suited for purification of atmospheric particle pollutants in the core tourist area were determined. A simple weighting coefficient was used to preliminarily evaluate the eight species: the retention quality of atmospheric particles on plant leaves, light shaded area and the reduction percentages of horizontal density before and after rain were set as subentries and sorted. The ordinal 
position of each plant was its weight coefficient, and the overall coefficient used for evaluation was obtained by adding the above three indexes together. A low coefficient indicated strong retention of atmospheric particles and self-purification by rain, and that the plants with low coefficient could simultaneously reduce the concentration of atmospheric particles and have a low effect on the plants themselves.

\section{Results and Discussion}

\subsection{Retention of Particle Weight on Leaves and Related Analysis}

The results of the retention of atmospheric particles on the main plant leaves at each sampling site of the Mount Wutai scenic area are shown in Figure 2. Before rain, the particle retention on leaves varied in the range of $6.95 \pm 1.55$ to $38.60 \pm 18.32 \mathrm{mg} / \mathrm{cm}^{2}$, and the decreasing order of particle retention quality per unit of leaf area was Po. davidiana, B. platyphylla, R. xanthina, R. hugonis, V. negundo var. heterophylla, Pe. sepium, S. salicifolia and Pi. tabuliformis. After rain, the atmospheric suspended particle retention volume on leaves varied in the range of $0.65 \pm 0.23$ to $3.50 \pm 1.83 \mathrm{mg} / \mathrm{cm}^{2}$, with decreasing order of particle retention quality per unit of leaf area of Po. davidiana, B. platyphylla, S. salicifolia, Pe. sepium, V. negundo var. heterophylla, R. xanthina, R. hugonis and Pi. tabuliformis.

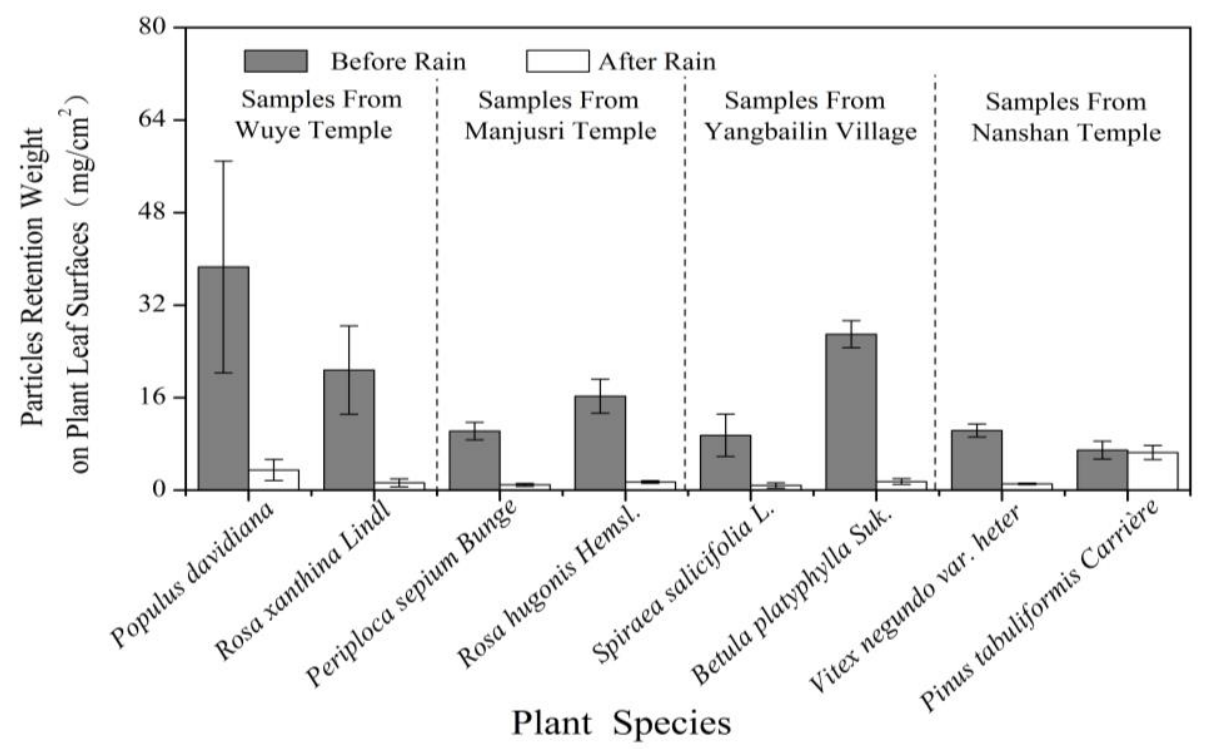

Figure 2. The particle retention quality of different plant leaves.

After washing by rain, the removal of retained particles per unit area of leaves of Po. davidiana, R. xanthina, Pe. sepium, R. hugonis, S. salicifolia, B. platyphylla, V. negundo var. heterophylla and Pi. tabuliformis was $35.10 \pm 2.17,25.48 \pm 1.20,9.30 \pm 0.07,14.83 \pm 0.76,8.65 \pm 0.69,19.50 \pm 1.91$, $9.23 \pm 0.31$ and $0.42 \pm 0.31 \mathrm{~g} / \mathrm{cm}^{2}$, respectively. The removal percentages of atmospheric particles on leaves of broad-leaved plants were reduced by $89.34 \%-94.44 \%$ (maximum value for B. platyphylla), with a much lower removal percentage on needle surfaces for Pi. tabuliformis (6.11\%).

\subsection{Shaded Area by Particles Retained on Leaf Surfaces and Related Analysis}

The light shaded areas by particles retained on leaves are shown in Figure 3. Before rain, the shaded areas from particles on leaves were in the range of $7.25 \pm 0.04$ (Pi. tabuliformis) to $126.50 \pm 6.66 \mathrm{~cm}^{2} /$ leaf (Po. davidiana). The leaf area of Po. davidiana shaded by particles was the largest, while the shaded needle area of Pi. tabuliformis was the smallest. After rain, the shaded areas due to particles on leaves varied in the range of $4.26 \pm 0.02$ (Pi. tabuliformis) to $45.96 \pm 2.42 \mathrm{~cm}^{2} /$ leaf (Po. davidiana). 


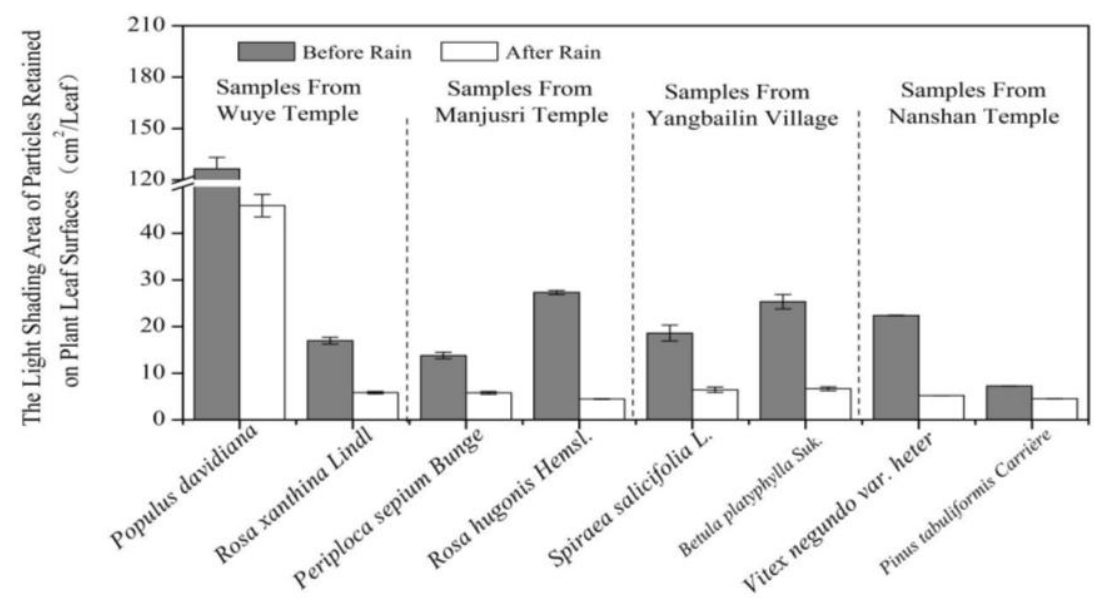

Plant Species

Figure 3. Light shaded area caused by particles on different plant leaves.

After being washed by rain, the shaded area on leaves of Po. davidiana, R. xanthina, Pe. sepium, R. hugonis, S. salicifolia, B. platyphylla, V. negundo var. heterophylla and Pi. tabuliformis was reduced to $80.54 \pm 4.24,18.65 \pm 1.14,8.01 \pm 0.40,22.86 \pm 0.35,12.18 \pm 1.11,11.15 \pm 0.48,17.19 \pm 0.05$ and $2.72 \pm 0.01 \mathrm{~cm}^{2} /$ leaf, respectively. There was a low reduction percentage in the shaded area on needles of Pi. tabuliformis (37.54\%); however, those of the broad-leaved plants were in the range of $58.085 \%-83.68 \%$ (maximum for $R$. hugonis), and all species had reductions of $>50 \%$ in shaded area.

\subsection{Analysis of Horizontal Density of Particles Retained on Leaves and the Purification Effect}

Before rain, the horizontal density of the atmospheric particles retained on plant leaves in the core area of the Mount Wutai scenic area (Figure 4) varied in the range of $110 \pm 2$ (Pi. tabuliformis) to $255 \pm 11$ per $\mathrm{cm}^{2}$ (Po. davidiana).

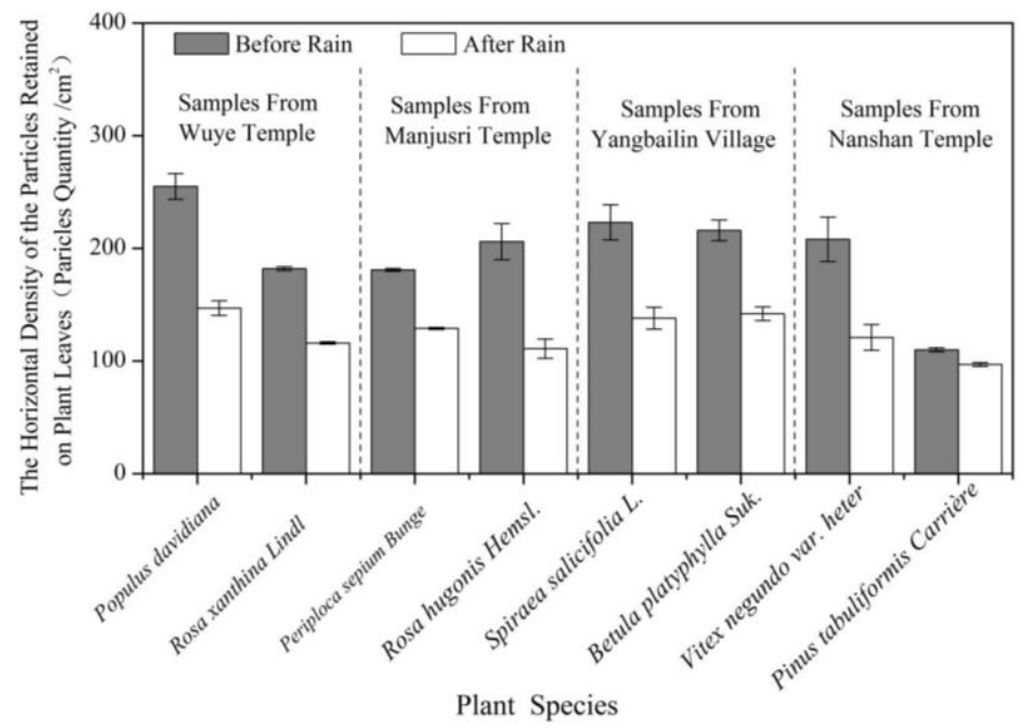

Figure 4. Horizontal density of atmospheric particles on different plant leaves.

After rain, the horizontal density of particles retained on leaves varied in the range of $97 \pm 2$ (Pi. tabuliformis) to $147 \pm 7$ per $\mathrm{cm}^{2}$ (Po. davidiana). After leaves were washed by rain, the horizontal densities of particles on leaves of Po. davidiana, R. xanthina, Pe. sepium, R. hugonis, S. salicifolia, B. platyphylla, V. negundo var. heterophylla and Pi. tabuliformis were reduced to $108 \pm 5,74 \pm 3,52 \pm 1$, 
$95 \pm 7,85 \pm 6,66 \pm 1,87 \pm 8$ and $13 \pm 1$ per $\mathrm{cm}^{2}$, respectively. The lowest reduction percentage in horizontal density of particles was on needles of Pi. tabuliformis $(11.82 \%)$, and for the broad-leaved plants, was in the range of $28.73 \%-46.12 \%$ (maximum for $R$. hugonis).

\subsection{Evaluation and Analysis of Purification Capacity of Particulate Pollution Retained on Leaf Surfaces}

The retention and absorption effects of vegetation generally have positive influences on the removal of atmospheric particles, and excess atmospheric particles have some negative effects on plant growth; however, the removal of particles by vegetation plays the leading role [20]. The evaluation results (Table 1) were used to determine the plants best suited for purification of atmospheric particle pollutants. In this study, the three indexes of eight kinds of plants have been ranked (the ranked number is $1,2,3, \ldots, 8)$ and the ranked number was added to attain the total evaluation coefficient. The process does not involve parallel testing and statistical analysis.

The three broad-leaved plants in the area with leaf surfaces that had stronger retention and purification capabilities for atmospheric particles were R. hugonis, Po. davidiana and B. platyphylla (Table 1). The broad-leaved plants had very significant retention effects on atmospheric particles. Research has shown that there are three different methods for plant leaves to adsorb atmospheric particles-retention, attachment and adhesion-and there are differences in the mechanism of action among the different adsorption modes [21,22].

Retention and attachment are the methods by which most broad-leaved plants adsorb atmospheric particles. In retention, wind speed is reduced by the airflow barrier of plant branches and leaves, and particulate pollutants in the air are captured and fixed on leaf surfaces through the rough leaf epidermis and cuticle characteristics. These retained particles are easily moved back into the air under the effect of increased wind speed and other external forces. The effects of retaining particles by attachment are more stable, and it is difficult for wind to blow particles away [23]. In addition, broad-leaved plants have flourishing crown canopies, and higher transpiration than needle-leaved plants. They can reduce atmospheric temperature, regulate the micro-region climate and effectively reduce the generation of secondary pollutants [24]. Broad-leaved plant leaves have characteristics that include deep grooves with large intervals on leaf surfaces, high stomatal density, abundant leaf hairs and good wettability, which are beneficial for leaves to retain particles. Simultaneously, after a certain period of retaining particles, most particles and water-soluble pollutants on leaves are cleaned through the washing of rainfall [11], and so most adsorption and photosynthetic capacities are restored [25]. Therefore, the research results indicate that $R$. hugonis, Po. davidiana and B. platyphylla are appropriate species for the purification of atmospheric particulate pollutants in the core area of the Mount Wutai scenic area, and they could be massively planted to prevent and control atmospheric pollution by particulate matter.

Needle-leaved plants use special secretions on leaf surfaces to adsorb atmospheric particles [26]. The only needle-leaved plant in this study was Pi. tabuliformis, which had an abundant wax layer secreted and attached to leaf surfaces—-thus providing a different mechanism of retaining particles compared to broad-leaved plants. Previous research indicated that needle-leaved trees with more complex fine-needle leaf structures had higher particle capture and concentration efficiency. The wax content in leaves was significantly positively correlated with dust-retention quantity [27], the wax content on leaf surfaces was significantly correlated with the amount of fine particles within the wax layer [28] and thus the important characteristics of dust-retention capability were embodied in leaf wax layers. Although much research has shown that plants of the Pinaceae can strongly adsorb atmospheric particles, less attention has been paid to the migration and transformation of pollutants carried by adsorbed particles on needles. However, the content of phthalic acid esters (PAEs) in superficial rhizosphere soil was positively correlated with their content in pine needles, wherein the PAEs under Pinaceae plants accumulated by gravitational settling of particles and the adsorbed particulate pollutants in pine needles [29]. 
Table 1. Evaluation results for the purification capacity coefficient of atmospheric particulate pollutants by the main plants in the Mount Wutai scenic area.

\begin{tabular}{|c|c|c|c|c|c|c|c|c|c|}
\hline \multicolumn{2}{|c|}{ Evaluation Item/Plant } & \multirow{2}{*}{$\frac{\text { Po. davidiana }}{1}$} & \multirow{2}{*}{$\frac{\text { R. xanthina }}{3}$} & \multirow{2}{*}{$\frac{\text { Pe. sepium }}{6}$} & \multirow{2}{*}{$\frac{\text { R. hugonis }}{4}$} & \multirow{2}{*}{$\frac{\text { S. salicifolia }}{7}$} & \multirow{2}{*}{$\frac{\text { B. platyphylla }}{2}$} & \multirow{2}{*}{$\begin{array}{c}\begin{array}{l}\text { V. negundo var. } \\
\text { heterophylla }\end{array} \\
5\end{array}$} & \multirow{2}{*}{$\frac{\text { Pi. tabuliformis }}{8}$} \\
\hline Sub-coefficient of & Before rain & & & & & & & & \\
\hline $\begin{array}{l}\text { particle retention } \\
\text { quality }\end{array}$ & $\begin{array}{c}\text { Removal percentage } \\
\text { after rain }\end{array}$ & 6 & 2 & 5 & 3 & 4 & 1 & 7 & 8 \\
\hline \multirow{2}{*}{$\begin{array}{l}\text { Sub-coefficient of } \\
\text { particle shaded area }\end{array}$} & \multirow{2}{*}{$\begin{array}{c}\text { Before rain } \\
\text { Removal percentage } \\
\text { after rain }\end{array}$} & 1 & 6 & 7 & 2 & 5 & 3 & 4 & 8 \\
\hline & & 6 & 4 & 7 & 1 & 5 & 3 & 2 & 8 \\
\hline \multirow{2}{*}{$\begin{array}{l}\text { Sub-coefficient of } \\
\text { particle horizontal } \\
\text { density }\end{array}$} & \multirow{2}{*}{$\begin{array}{c}\text { Before rain } \\
\text { Removal percentage } \\
\text { after rain }\end{array}$} & 1 & 6 & 7 & 5 & 2 & 3 & 4 & 8 \\
\hline & & 2 & 5 & 7 & 1 & 4 & 6 & 3 & 8 \\
\hline \multicolumn{2}{|c|}{ Total evaluation coefficient } & 17 & 26 & 39 & 16 & 27 & 18 & 25 & 48 \\
\hline
\end{tabular}


Because of the frequent incense-burning religious activities in the core area of Mount Wutai, there is also much burning of the plastic oblations and their plastic packages, and PAEs are widely applied in these plastic products [30]. After they are burned and released into the atmosphere, the enrichment of pollutants in the trees and rhizosphere soil is easily caused by the long-term adsorption by pine needles, which raises the pollutant concentration in certain regions, and not only harms the plants themselves but also affects the surrounding soil environment. Moreover, there are some lipophilic organic pollutants in atmospheric particulate pollutants, which can permeate into leaf wax layers [31]. Therefore, the wax lipid layer of pine needles might be a passive accumulator of persistent organic pollutants (POPs), reducing the natural degradation rate and becoming "POPs Chrysophoron" [32-35], which is very unfavorable for reducing the total quantity of regional organic pollutants. Therefore, Pinaceae are not appropriate for the purification of atmospheric particulate pollutants in the core area of the Mount Wutai scenic area.

In conclusion, before and after rain, among the investigated plants, Po. davidiana had the maxima for atmospheric particle quality retained on leaf surfaces, light shaded area and horizontal density, while Pi. tabuliformis had the minima of these three indexes. However, after the scouring effect of rainfall, the removal percentage of atmospheric particles retained on leaves was highest for B. platyphylla, and the reduction percentages in the light shaded area and horizontal density of atmospheric particles retained on leaves were highest for $R$. hugonis. The most appropriate species for purification of atmospheric particles in Mount Wutai were R. hugonis, Po. davidiana and B. platyphylla. The broad-leaved plants with lower dust-retention abilities than the above three species (e.g., R. xanthina, Pe. sepium, S. salicifolia and V. negundo var. heterophylla) could be alternative plants for purification. However, because of its specific dust-retention characteristics and the migration of pollutants in pine needles, Pi. tabuliformis is not recommended for purification of atmospheric particles in the core area of Mount Wutai scenic area.

During the period of 21-27 August in 2014, the daily average wind speeds of Mount Wutai are $3.5 \mathrm{~m} / \mathrm{s}, 4.0 \mathrm{~m} / \mathrm{s}, 4.0 \mathrm{~m} / \mathrm{s}, 4.4 \mathrm{~m} / \mathrm{s}, 3.7 \mathrm{~m} / \mathrm{s}, 3.1 \mathrm{~m} / \mathrm{s}$, and $3.6 \mathrm{~m} / \mathrm{s}$, i.e. no greater than $5 \mathrm{~m} / \mathrm{s}$. Therefore, the wind speed on Mount Wutai can hardly affect the amount of adsorption on the surface of the leaves. The average wind speed of Mount Wutai in August is $3.57 \pm 0.9 \mathrm{~m} / \mathrm{s}$, which is less than $5 \mathrm{~m} / \mathrm{s}$. The wind speed does not affect the adsorption of particles on the surface of the particles when the wind speed is less than $5 \mathrm{~m} / \mathrm{s}$ [36]. Therefore, the effect of wind speed on the particulate matter is almost negligible.

Conglutination is the way in which atmospheric particulate matter adheres to the surface of plant leaves by special secretions. The effect is so stable that neither rain nor general washing can completely remove the particles from the leaves $[31,37]$. No leaf surface roughness occurs in conifers; coniferous trees have long, slender needles, more complex branches and leaves are present the whole year. The particle adsorption ability of conifers is stronger than that of broadleaf trees, and conifers can secrete resin, decreasing the proportion of fine particles that can be dislodged. The average humidity of Mount Wutai is $72.8 \% \pm 15.6 \%$ in August, and the humidity may cause the viscosity of Pinus tabulaeformis secretions to decrease. In such a high humidity environment, the pine-adsorbing particle effect will be worse. The removal rate of particles by needles under high humidity will continue to increase because of the reduction in secretion viscosity. However, in comparison with the seven other types of plants, the particles percentage in pine leaves after rain is still the lowest. Therefore, the pine tree is not suitable used for purifying the environment in Mount Wutai.

\section{Conclusions}

Based on the analysis of the retention volume of atmospheric particles, light shaded characteristics of leaf surfaces and the retention density of particles on leaves of eight tree species, the following conclusions were drawn.

Populus davidiana, B. platyphylla and R. hugonis had better retention effects on atmospheric suspended particles, and particulate matter on their leaf surfaces was effectively washed off after rain. 
Comparatively speaking, the needles of Pi. tabuliformis had greater retention efficiency of particulate matter. The retention of suspended matter or the removal of particulate matter after rain for the broad-leaved species including R. xanthina, Pe. sepium, S. salicifolia and V. negundo var. heterophylla fell between the results for Pi. tabuliformis and Po. davidiana, B. platyphylla and R. hugonis.

It is suggested that tree species selection for purification of atmospheric particulate pollutants in the core area of the Mount Wutai scenic area (i.e., incense-burning aggregated area of Wu Ye Temple, transportation hub of Manjusri Temple and the residential district of Yang Bai Lin Village) should be based on Po. davidiana, R. hugonis and B. platyphylla. Although the dust-retention capabilities of the broad-leaved plants R. xanthina, Pe. sepium, S. salicifolia and V. negundo var. heterophylla were lower than the three above-mentioned plants, they could be alternative plants for purification and could be planted in the primeval forest area of Nanshan Temple. Because pine needles have a lower purification capability associated with atmospheric particulate pollutants, Pi. tabuliformis is not recommended for purification of atmospheric particulate pollutants in the core area of the Mount Wutai scenic area. The results of this study will serve as a guide in the screening of tree species for atmospheric purification in Mount Wutai and related Buddhism scenic areas.

Acknowledgments: This work was supported by the Science and Technology Key Project of Shanxi Province (funded social development) (No. 20120313011-1) and Shanxi Agricultural University Talent recruitment project (No. XB2011017).

Author Contributions: Fenwu Liu and Wenhua Fan conceived and designed the experiments. Shuai Shi, Zhihui Wu and Fenwu Liu collected and analyzed the data. Shuai Shi and Zhihui Wu wrote the paper.

Conflicts of Interest: The authors declare no conflict of interest.

\section{Abbreviations}

The following abbreviations are used in this manuscript:

$\begin{array}{ll}\text { Po. Davidiana } & \text { Populus davidiana } \\ \text { R. Hugonis } & \text { Rosa hugonis Hemsl. } \\ \text { B. Platyphylla } & \text { Betula platyphylla Suk. } \\ \text { R. Xanthina } & \text { Rosa xanthina Lindl. } \\ \text { Pe. Sepium } & \text { Periploca sepium Bunge } \\ \text { S. Salicifolia } & \text { Spiraea salicifolia L. } \\ \text { V. negundo var. Heterophylla } & \text { Vitex negundo var. Heterophylla } \\ \text { Pi. Tabuliformis } & \text { Pinus tabuliformis Carrière }\end{array}$

\section{References}

1. Nation Bureau of Statistics of the People's Republic of China. Available online: http:/ /data.stats.gov.cn/ easyquery.htm?cn=C01 (accessed on 26 February 2015).

2. China National Tourism Administration. Available online: http://www.cnta.gov.cn/xxfb/wxzl/201506/ t20150625_430725.shtml (accessed on 24 November 2011).

3. The Buddhist Association of China. China Buddhist Temple of 2010, Version 2; Chinese Buddhist Press: Hangzhou, China, 2010. (In Chinese)

4. Wang, B.; Lee, S.C.; Ho, K.F.; Kang, Y.M. Characteristics of emissions of air pollutants from burning of incense in temples, Hong Kong. Sci. Total Environ. 2007, 377, 52-60. [CrossRef] [PubMed]

5. Zhang, J.P.; Chen, W.J.; Li, J.N.; Yu, S.J.; Zhao, W.Z. VOCs and particulate pollution due to incense burning in temples, China. Procedia Eng. 2015, 121, 992-1000. [CrossRef]

6. Navasumrit, P.; Arayasiri, M.; Hiang, O.M.T.; Leechawengwongs, M.; Promvijit, J.; Choonvisase, S.; Chantchaemsai, S.; Nakngam, N.; Mahidol, C.; Ruchirawat, M. Potential health effects of exposure to carcinogenic compounds in incense smoke in temple workers. Chem. Biol. Interact. 2008, 173, 19-31. [CrossRef] [PubMed]

7. Nowak, D.J.; Crane, D.E.; Stevens, J.C. Air pollution removal by urban trees and shrubs in the United States. Urban For. Urban Green. 2006, 4, 115-123. [CrossRef] 
8. Schaubroeck, T.; Deckmyn, G.; Neirynck, J.; Staelens, J.; Adriaenssens, S.; Dewulf, J.; Muys, B.; Verheyrn, K. Multilayered modeling of particulate matter removal by a growing forest over time, from plant surface deposition to washoff via rainfall. Environ. Sci. Technol. 2014, 48, 10785-10794. [CrossRef] [PubMed]

9. Terzaghi, E.; Wild, E.; Zacchello, G.; Cerabolini, B.E.L.; Jones, K.C.; Guardo, A.D. Forest Filter Effect: Role of leaves in capturing/releasing air particulate matter and its associated PAHs. Atmos. Environ. 2013, 74, 378-384. [CrossRef]

10. Nguyen, T.; Yu, X.X.; Zhang, Z.M.; Liu, M.M.; Liu, X.H. Relationship between types of urban forest and $\mathrm{PM}_{2.5}$ capture at three growth stages of leaves. J. Environ. Sci.-China 2015, 27, 33-41. [CrossRef] [PubMed]

11. Wang, L.; Gong, H.L.; Liao, W.B.; Wang, Z. Accumulation of particles on the surface of leaves during leaf expansion. Sci. Total Environ. 2015, 532, 420-434. [CrossRef] [PubMed]

12. Liu, X.H.; Yu, X.X.; Zhang, Z.M. PM 2.5 concentration differences between various forest types and its correlation with forest structure. Atmosphere 2015, 6, 1801-1815. [CrossRef]

13. Rai, R.K. Impacts of particulate matter pollution on plants: Implications for environmental biomonitoring. Ecotoxicol. Environ. Saf. 2016, 129, 120-136. [CrossRef] [PubMed]

14. Prajapati, S.K.; Tripathi, B.D. Seasonal variation of leaf dust accumulation and pigment content in plant species exposed to urban particulates pollution. J. Environ. Qual. 2008, 37, 865-870. [CrossRef] [PubMed]

15. Corrêa, A.X.R.; Cotelle, S.; Millet, M.; Somensi, C.A.; Wagner, T.M.; Radetski, C.M. Genotoxicity assessment of particulate matter emitted from heavy-duty diesel-powered vehicles using the in vivo Vicia faba L. micronucleus test. Ecotoxicol. Environ. Saf. 2016, 127, 199-204. [CrossRef] [PubMed]

16. Arrivabene, H.P.; Souza, I.C.; Có, W.L.O.; Conti, M.M.; Wunderlin, D.A.; Milanez, C.R.D. Effect of pollution by particulate iron on the morphoanatomy, histochemistry, and bioaccumulation of three mangrove plant species in Brazil. Chemosphere 2015, 127, 27-34. [CrossRef] [PubMed]

17. Wu, Z.H.; Liu, F.W.; Fan, W.H. Characteristics of $\mathrm{PM}_{10}$ and $\mathrm{PM}_{2.5}$ at Mount Wutai Buddhism scenic spot, Shanxi, China. Atmosphere 2015, 6, 1195-1210. [CrossRef]

18. Wu, Z.H.; Fan, W.H.; Liu, F.W.; Duan, Q.Q.; Wang, K.; Liu, X.X. Air quality and its temporal and spatial characteristic analysis in Mount Wutai scenic area. Environ. Pollut. Control 2015, 06, 63-68.

19. Plant Photo Bank of China, PPBC. Available online: http://www.plantphoto.cn/ (accessed on 23 July 2016).

20. Janhäll, S. Review on urban vegetation and particle air pollution-deposition and dispersion. Atmos. Environ. 2015, 105, 130-137. [CrossRef]

21. Tiwary, A.; Sinnett, D.; Peachey, C.; Chalabi, Z.; Vardoulakis, S.; Fletcher, T.; Leonardi, G.; Grundy, C.; Azapagic, A.; Hutchings, T.R. An integrated tool to assess the role of new planting in $\mathrm{PM}_{10}$ capture and human health benefits: A case study in London. Environ. Pollut. 2009, 157, 2645-2653. [CrossRef] [PubMed]

22. Tallis, M.; Taylor, G.; Sinnett, D.; Freer-Smith, P. Estimating the removal of atmospheric particulate pollution by the urban tree canopy of London, under current and future environments. Landscape Urban Plan. 2011, 103, 129-138. [CrossRef]

23. Prusty, B.A.K.; Mishra, P.C.; Azeez, P.A. Dust accumulation and leaf pigment content in vegetation near the national highway at Sambalpur, Orissa, India. Ecotoxicol. Environ. Saf. 2005, 60, 228-235. [CrossRef] [PubMed]

24. Pankow, J.F.; Marks, M.C.; Barsanti, K.C.; Mahmud, A.; Asher, W.E.; Li, J.Y.; Ying, Q.; Jathar, S.H.; Kleeman, M.J. Molecular view modeling of atmospheric organic particulate matter: Incorporating molecular structure and co-condensation of water. Atmos. Environ. 2015, 122, 400-408. [CrossRef]

25. Ouyang, W.; Guo, B.B.; Cai, G.Q.; Li, Q.; Han, S.; Liu, B.; Liu, X.G. The washing effect of precipitation on particulate matter and the pollution dynamics of rainwater in downtown Beijing. Sci. Total Environ. 2015, 505, 306-314. [CrossRef] [PubMed]

26. Beckett, K.P.; Freer-Smith, P.H.; Taylor, G. Particulate pollution capture by urban trees: Effect of species and wind speed. Glob. Chang. Biol. 2000, 6, 995-1103. [CrossRef]

27. Sæbø, A.; Popek, R.; Nawrot, B.; Hanslin, H.M.; Gawronska, H.; Gawronski, S.W. Plant species differences in particulate matter accumulation on leaf surfaces. Sci. Total Environ. 2012, 427, 347-354. [CrossRef] [PubMed]

28. Dzierzanowski, K.; Popek, R.; Gawrońska, H.; Saebø, A.; Gawroński, S.W. Deposition of particulate matter of different size fractions on leaf surfaces and in waxes of urban forest species. Int. J. Phytoremediat. 2011, 13, 1037-1046. [CrossRef] [PubMed]

29. Wang, W.X.; Fan, C.Q. Gas/solid particulate phthalic esters (PAEs) in Masson pine (Pinus massoniana L.) needles and rhizosphere surface soils. J. Hazard Mater. 2014, 276, 149-156. [CrossRef] [PubMed] 
30. Net, S.; Delmont, A.; Sempéré, R.; Paluselli, A.; Ouddane, B. Reliable quantification of phthalates in environmental matrices (air, water, sludge, sediment and soil): A review. Sci. Total Environ. 2015, 515-516, 162-180. [CrossRef] [PubMed]

31. Popek, R.; Gawrońska, H.; Wrochna, M.; Gawroński, S.W. Particulate matter on foliage of 13 woody species: Deposition on surfaces and phytostabilisation in waxes a 3-year study. Int. J. Phytoremediat. 2013, 15, $245-256$. [CrossRef] [PubMed]

32. Dolinová, J.; Klánová, J.; Klán, P.; Holoubek, I. Photodegradation of organic pollutants on the spruce needle wax surface under laboratory conditions. Chemosphere 2004, 57, 1399-1407. [CrossRef] [PubMed]

33. Klánová, J.; Čupr, P.; Baráková, D.; Šeda, Z.; Anděl, P.; Holoubek, I. Can pine needles indicate trends in the air pollution levels at remote sites? Environ. Pollut. 2009, 157, 3248-3254. [CrossRef] [PubMed]

34. Iozza, S.; Schmid, P.; Oehme, M. Development of a comprehensive analytical method for the determination of chlorinated paraffins in spruce needles applied in passive air sampling. Environ. Pollut. 2009, 157, 3218-3224. [CrossRef] [PubMed]

35. Li, Y.G.; Chen, B.L.; Zhu, L.Z. Single-solute and bi-solute sorption of phenanthrene and pyrene onto pine needle cuticular fractions. Environ. Pollut. 2010, 158, 2478-2484. [CrossRef] [PubMed]

36. Ould-Dada, Z.; Baghini, N.M. Resuspension of small particles from tree surfaces. Atmos. Environ. 2001, 35, 3799-3809. [CrossRef]

37. Freer-Smith, P.H.; Beckett, K.P.; Taylor, G. Deposition velocities to sorbus aria, Acer campestre, populus deltoides $\times$ trichocarpa "beaupré", pinus nigra and $\times$ Cupressocyparis leylandii for coarse, fine and ultra-fine particles in the urban environment. Environ. Pollut. 2005, 133, 157-167. [CrossRef] [PubMed]

(C) 2016 by the authors; licensee MDPI, Basel, Switzerland. This article is an open access article distributed under the terms and conditions of the Creative Commons Attribution (CC-BY) license (http://creativecommons.org/licenses/by/4.0/). 